\title{
Low sensitivity of Bartonella henselae PCR in serum samples of patients with cat-scratch disease lymphadenitis
}

Cat-scratch disease (CSD) is caused by Bartonella henselae and usually presents as self-limiting lymphadenitis. Invasive procedures are often needed to confirm the diagnosis by PCR on lymph node or other material, because culture and serological tests have low sensitivity (Bergmans et al., 1997; La Scola \& Raoult, 1999; Fournier et al., 2002). Recently, Arvand \& Schäd (2006) described isolation of $B$. henselae DNA from peripheral blood of a CSD patient 3 and 4 months after a cat scratch. They suggest that detection of $B$. henselae DNA in blood may prove useful, especially in cases where lymphadenectomy or biopsy is not feasible or serological results are equivocal.

We evaluated the use of $B$. henselae DNA detection in serum samples of a group of 18 CSD patients (mean age 29 years) with lymphadenopathy whose lymph node specimens tested positive by $B$. henselae PCR. B. henselae DNA was detected in lymph node material by a genotypespecific 16S rRNA PCR as described previously (Bergmans et al., 1996, 1997). Genotype I was detected in 13 (72\%) cases and genotype II in 5 (28\%) cases.

Serological testing by immunofluorescence assay showed positive $B$. henselae IgM in 15 $(83 \%)$ cases and IgG in $12(67 \%)$ cases. The patients had symptoms for 8-42 days (median 20 days), with suppuration in 15 cases. Cat contact was noted in 13 cases (5 unknown). The collection of serum occurred 0-17 days (median 5 days) before tissue sampling. A 'control' group consisted of 50 patients (mean age 35 years) who were clinically suspect for CSD but tested negative for $B$. henselae IgM antibodies using an in-house-prepared immunofluorescence assay as described previously (Bergmans et al., 1997; Vermeulen et al., 2007). A real-time PCR assay targeted at the heat-shock protein groEL was used to detect $B$. henselae DNA in all serum samples (Diederen et al., 2007a).
Of the 18 patients with proven CSD, 3 $(18 \%)$ sera tested positive in real-time PCR for B. henselae DNA, with a mean cycle threshold value of 38 (range 37.739.3). Two of these patients were infected with $B$. henselae genotype I and one with genotype II. The 50 'control' serum samples all tested negative in PCR.

Detection of $B$. henselae DNA has been described consistently in feline blood samples, reflecting long-lasting bacteraemia in cats. In humans, detection of $B$. henselae DNA in peripheral blood of CSD patients has been described sporadically (Del Prete et al., 2000a, b; Tsukahara et al., 2001; Arvand \& Schäd, 2006). We confirm that in a small proportion of CSD cases it is possible to detect $B$. henselae DNA in serum. This may reflect temporary bacteriaemia or the shed of bacterial breakdown products during the phase of suppuration. The low sensitivity (18\%) found in our study suggests that PCR using serum has limited value in a routine clinical microbiology laboratory.

Generally, serum samples from patients with lymphadenopathy are readily available as these are often stored after serological testing. Detection of bacterial DNA in serum samples has proven to be useful in other diseases such as Legionnaires' disease (Diederen et al., 2007b). However, we found a low sensitivity of PCR on serum samples in CSD. This may be due to loss of bacterial DNA after centrifugation and storage at $-20{ }^{\circ} \mathrm{C}$. Also, DNA may be absent in serum as $B$. henselae can invade erythrocytes (Pitassi et al., 2007). Based on that theory, PCR could be more valuable on plasma or whole blood specimens. Therefore, we collected both plasma and whole blood samples from five new CSD patients with positive serological results (IgM B. henselae positive) and/or positive $B$. henselae PCR on lymph node specimens. None of the plasma nor whole blood samples tested positive in real-time PCR for $B$. henselae DNA. The number of samples tested is too small to draw strong conclusions, though taking plasma or whole blood is probably not the ideal. Further prospective studies are needed to determine the exact sensitivity and specificity of Bartonella-specific PCR in serum, plasma and whole blood samples and to determine the optimal moment of sample taking during CSD.

\section{Marijn J. Vermeulen, ${ }^{1}$ Bram M. W. Diederen, ${ }^{2}$ Harold Verbakel ${ }^{3}$ and Marcel F. Peeters ${ }^{3}$ \\ ${ }^{1}$ VU University Medical Center, Department of Pediatrics, PO Box 7057, 1007 MB Amsterdam, The Netherlands
${ }^{2}$ Regional Laboratory of Public Health, The Netherlands
${ }^{3}$ Regional Laboratory of Public Health, PO Box 747, 5000 AS Tilburg, The Netherlands Boerhaavelaan 26, 2035 RC Haarlem,}

\section{Correspondence: Marijn J. Vermeulen (m.vermeulen@vumc.nl)}

Arvand, M. \& Schäd, G. S. (2006). Isolation of Bartonella henselae DNA from the peripheral blood of a patient with cat scratch disease up to 4 months after the cat scratch injury. J Clin Microbiol 44, 2288-2290.

Bergmans, A. M., Schellekens, J. F., van Embden, J. D. \& Schouls, L. M. (1996). Predominance of two Bartonella henselae variants among cat-scratch disease patients in the Netherlands. J Clin Microbiol 34, 254-260.

Bergmans, A. M., Peeters, M. F., Schellekens, J. F., Vos, M. C., Sabbe, L. J., Ossewaarde, J. M., Verbakel, H., Hooft, H. J. \& Schouls, L. M. (1997). Pitfalls and fallacies of cat scratch disease serology: evaluation of Bartonella henselae-based indirect fluorescence assay and enzyme-linked immunoassay. J Clin Microbiol 35, 1931-1937.

Del Prete, R., Fumarola, D., Fumarola, L. \& Miragliotta, G. (2000a). Detection of Bartonella henselae and Afipia felis DNA by polymerase chain reaction in specimens from patients with 
cat scratch disease. Eur J Clin Microbiol Infect Dis 19, 964-967.

Del Prete, R., Fumarola, D., Ungari, S., Fumarola, L. \& Miragliotta, G. (2000b). Polymerase chain reaction detection of Bartonella henselae bacteraemia in an immunocompetent child with cat-scratch disease. Eur J Pediatr 159, 356-359.

Diederen, B. M., Vermeulen, M. J., Verbakel, H., van der Zee, A., Bergmans, A. \& Peeters, M. F.

(2007a). Evaluation of an internally controlled realtime polymerase chain reaction assay targeting the groEL gene for the detection of Bartonella spp. DNA in patients with suspected cat-scratch disease. Eur J Clin Microbiol Infect Dis 26, 629-633.
Diederen, B. M., de Jong, C. M., Marmouk, F., Kluytmans, J. A., Peeters, M. F. \& Van der Zee, A. (2007b). Evaluation of real-time PCR for the early detection of Legionella pneumophila DNA in serum samples. J Med Microbiol 56, 94-101.

Fournier, P. E., Robson, J., Zeaiter, Z., McDougall, R., Byrne, S. \& Raoult, D. (2002). Improved culture from lymph nodes of patients with cat scratch disease and genotypic characterization of Bartonella henselae isolates in Australia. J Clin Microbiol 40, 3620-3624.

La Scola, B. \& Raoult, D. (1999). Culture of Bartonella quintana and Bartonella henselae from human samples: a 5-year experience (1993 to 1998). J Clin Microbiol 37, 1899-1905.
Pitassi, L. H., Magalhaes, R. F., Barjas-Castro, M. L., de Paula, E. V., Ferreira, M. R. \& Velho, P. E. (2007). Bartonella henselae infects human erythrocytes. Ultrastruct Pathol 31, 369-372.

Tsukahara, M., lino, H., Ishida, C., Murakami, K., Tsuneoka, H. \& Uchida, M. (2001). Bartonella henselae bacteraemia in patients with cat scratch disease. Eur J Pediatr 160, 316.

Vermeulen, M. J., Herremans, M., Verbakel, H., Bergmans, A. M., Roord, J. J., van Dijken, P. J. \& Peeters, M. F. (2007). Serological testing for Bartonella henselae infections in The Netherlands: clinical evaluation of immunofluorescence assay and ELISA. Clin Microbiol Infect 13, 627-634. 